\title{
A STUDY ON THE PATTERNS AND VARIATIONS IN THE TERTIARY BRONCHI OF RIGHT LOWER LOBE OF HUMAN LUNG
}

\author{
Rani Raphael $M^{1}$, Rajad $R^{2}$
}

${ }^{1}$ Assistant Professor, Department of Anatomy, Government T. D. Medical College, Alappuzha, Kerala. ${ }^{2}$ Assistant Professor, Department of Anatomy, Government T. D. Medical College, Alappuzha, Kerala.

\section{ABSTRACT}

\section{BACKGROUND}

Ten bronchopulmonary segments are described for each lung. Foreign bodies and other aspirated materials tend to enter the right instead of the left bronchus, because the former is wider and more in continuation with the trachea and from there to the apical bronchus of the lower lobe. So the right lower lobe was selected for a study by dissection. The bronchopulmonary segments of inferior lobe of right lung are 5 in number- superior (apical), medial basal, anterior basal, lateral basal and posterior basal. Some workers consider an occasional segment, which arises as a separate bronchus from the right inferior lobar bronchus below the apical bronchus, which they term as subapical segment.

\section{MATERIALS AND METHODS}

56 human cadaveric right lungs from the Department of Anatomy, Government T. D. Medical College, Alappuzha, Kerala, were dissected to visualise the bronchial tree. The lower lobar bronchus was identified to study its branching pattern to tertiary bronchi. The external length and diameter of the tertiary bronchi were measured using digital vernier calipers.

\section{RESULTS}

Apical $\left(\mathrm{B}^{6}\right)$, Lateral basal $\left(\mathrm{B}^{9}\right)$ and Posterior basal $\left(\mathrm{B}^{10}\right)$ segments were constantly present, whereas Medial basal $\left(\mathrm{B}^{7}\right)$ and $A n t e r i o r$ basal $\left(B^{8}\right)$ were seen in $89.3 \%$ and $96.4 \%$ respectively. A Subapical segment $\left(B^{*}\right)$ was seen in $17.9 \%$. Out of the studied bronchopulmonary segments, $\mathrm{B}^{6}$ had the maximum average external breadth $(5.5 \mathrm{~mm})$ and $\mathrm{B}^{9}$ the maximum average length $(1 \mathrm{~mm})$.

\section{CONCLUSION}

The tertiary bronchi may be of different patterns due to developmental variations. A thorough knowledge about the anatomic principles of bronchial branching and use of a lobe-based classification scheme will help in the recognition of tracheobronchial positional anomalies before performing diagnostic or therapeutic bronchoscopic procedures.

\section{KEYWORDS}

Bronchopulmonary Segment, Subapical Segment, Tertiary Bronchi, Right Lung.

HOW TO CITE THIS ARTICLE: Raphael RM, Rajad R. A study on the patterns and variations in the tertiary bronchi of right lower lobe of human lung. J. Evolution Med. Dent. Sci. 2017;6(50):3838-3840, DOI: 10.14260/Jemds/2017/0000

\section{BACKGROUND \\ The trachea divides into right and left principal bronchi; each principal bronchus divides into lobar bronchi; the lobar bronchi branches into tertiary bronchi. The tertiary bronchi are also called segmental bronchi, because it aerates a structurally separate, functionally independent unit of lung tissue called a bronchopulmonary segment. Each lung contains 10 bronchopulmonary segments. ${ }^{1}$ Foreign bodies and other aspirated material tend to enter the right instead of the left bronchus, because the former is wider and more in continuation with the trachea ${ }^{2}$; from there they usually pass into the lower lobe. The bronchopulmonary segments of right inferior lobe are 5 in number- superior (apical), medial basal, anterior basal, lateral basal and posterior basal. ${ }^{1}$ Some}

Financial or Other, Competing Interest: None.

Submission 19-05-2017, Peer Review 12-06-2017,

Acceptance 18-06-2017, Published 00-06-2017.

Corresponding Author:

Dr. Rajad R,

Assistant Professor,

Department of Anatomy,

Government T. D. Medical College,

Alappuzha, Kerala.

E-mail: r.rajad@gmail.com

DOI: $10.14260 /$ jemds $/ 2017 / 00$ workers consider an occasional segment, which arises as a separate bronchus from the right inferior lobar bronchus below the apical bronchus which they term as subapical segment.

The tertiary bronchi may be of different patterns due to developmental variations. They are usually asymptomatic, but should be recognised prior to lung resection to avoid complications, especially when video-assisted thoracoscopic surgery is performed. Also, the clinician should be aware of these anomalies before performing diagnostic or therapeutic bronchoscopic procedures. A thorough knowledge about the anatomic principles of bronchial branching and use of a lobebased classification scheme will help in the recognition of tracheobronchial positional anomalies. ${ }^{3}$

The objective of the present study was to determine the patterns and variations of the tertiary bronchi of right lower lobe. The right lower lobe was selected to be studied, because it is the commonest one affected in foreign body inhalation and aspiration. This study is justified by the comparatively lesser number of existing studies on the same in Kerala population and the need to compile data, which could be of clinical use in doing procedures like bronchoscopy. 


\section{MATERIALS AND METHODS}

A descriptional study of 56 human cadaveric right lungs from the Department of Anatomy, Government T. D Medical College, Alappuzha, Kerala was conducted. The right lungs which were removed after opening the thoracic cavity during routine dissection in the previous years were dissected out piecemeal to visualise the bronchial tree. The lower lobar bronchus was identified to study its branching pattern to tertiary bronchi. Length and diameter of the tertiary bronchi were measured using digital vernier calipers. They were photographed. Consecutive intact right lungs were included. Lungs with anomalies and pulmonary pathologies were excluded. The arithmetic mean was calculated for the length and external diameter of each tertiary bronchus (right lower lobe). Standard deviation was also calculated.

\section{RESULTS}

Boyden's nomenclature is the standard method followed for naming bronchopulmonary segments. ${ }^{4}$ Accordingly, bronchopulmonary segments of right inferior lobe are 5 in number- apical, medial basal, anterior basal, lateral basal and posterior basal and denoted by $\mathrm{B}^{6}, \mathrm{~B}^{7}, \mathrm{~B}^{8}, \mathrm{~B}^{9}$ and $\mathrm{B}^{10}$. In some cases, a subapical bronchus may be present, which is represented as $\mathrm{B}^{*}$. The present study also follows this.

Of the 56 right lungs studied, the distributions of various tertiary bronchi were as shown in Table 1 .

\begin{tabular}{|c|c|c|}
\hline Tertiary Bronchus & Number (Out of 56) & Percentage \\
\hline Apical $\left(B^{6}\right)$ & 56 & 100 \\
\hline Medial basal $\left(\mathrm{B}^{7}\right)$ & 50 & 89.3 \\
\hline Anterior basal $\left(\mathrm{B}^{8}\right)$ & 56 & 100 \\
\hline Lateral basal $\left(\mathrm{B}^{9}\right)$ & 54 & 96.4 \\
\hline Posterior basal $\left(\mathrm{B}^{10}\right)$ & 56 & 100 \\
\hline Subapical (B*) & 10 & 17.9 \\
\hline
\end{tabular}

\begin{tabular}{|c|c|c|}
\hline $\begin{array}{c}\text { Tertiary } \\
\text { Bronchus }\end{array}$ & $\begin{array}{c}\text { Length } \\
\text { ( } \pm \text { S.D) }\end{array}$ & $\begin{array}{c}\text { Breadth (External) } \\
\text { ( } \pm \text { S.D) }\end{array}$ \\
\hline Apical $\left(\mathrm{B}^{6}\right)$ & $0.8 \pm 0.12$ & $5.5 \pm 0.37$ \\
\hline Medial basal $\left(\mathrm{B}^{7}\right)$ & $0.8 \pm 0.12$ & $4.1 \pm 0.20$ \\
\hline Anterior basal $\left(\mathrm{B}^{8}\right)$ & $0.9 \pm 0.15$ & $4.8 \pm 0.21$ \\
\hline Lateral basal $\left(\mathrm{B}^{9}\right)$ & $1.0 \pm 0.1$ & $4.1 \pm 0.20$ \\
\hline Posterior basal $\left(\mathrm{B}^{10}\right)$ & $0.6 \pm 0.17$ & $4.8 \pm 0.17$ \\
\hline Subapical $\left(\mathrm{B}^{*}\right)$ & $0.6 \pm 0.14$ & $2.8 \pm 0.64$ \\
\hline Table 2. Average Length and Breadth of Tertiary Bronchi \\
of Right Lower Lobe (in mm)
\end{tabular}

The observed branching patterns of the lower lobar bronchus were as follows. The $\mathrm{B}^{6}$ was seen arising as a separate stem in $82 \%$, whereas in $16 \%$ it was $\mathrm{B}^{6}+\mathrm{B}^{*}$ and a bizarre pattern in $2 \%$. A basal bronchial trunk arising below $\mathrm{B}^{6}+\mathrm{B}^{*}$ bifurcated into anteromedial stem bronchus and posterolateral stem bronchus in $86 \%$ of the specimen. In $10 \%$ the basal bronchial trunks were trifurcating into $\mathrm{B}^{8}, \mathrm{~B}^{9}$ and $\mathrm{B}^{10}$ (if $\mathrm{B}^{7}$ absent) or $\mathrm{B}^{7+8}, \mathrm{~B}^{9}, \mathrm{~B}^{10}$ (if $\mathrm{B}^{7}$ present). In $4 \%$ it divided into four branches $-\mathrm{B}^{7}, \mathrm{~B}^{8}, \mathrm{~B}^{9}$ and $\mathrm{B}^{10}$.

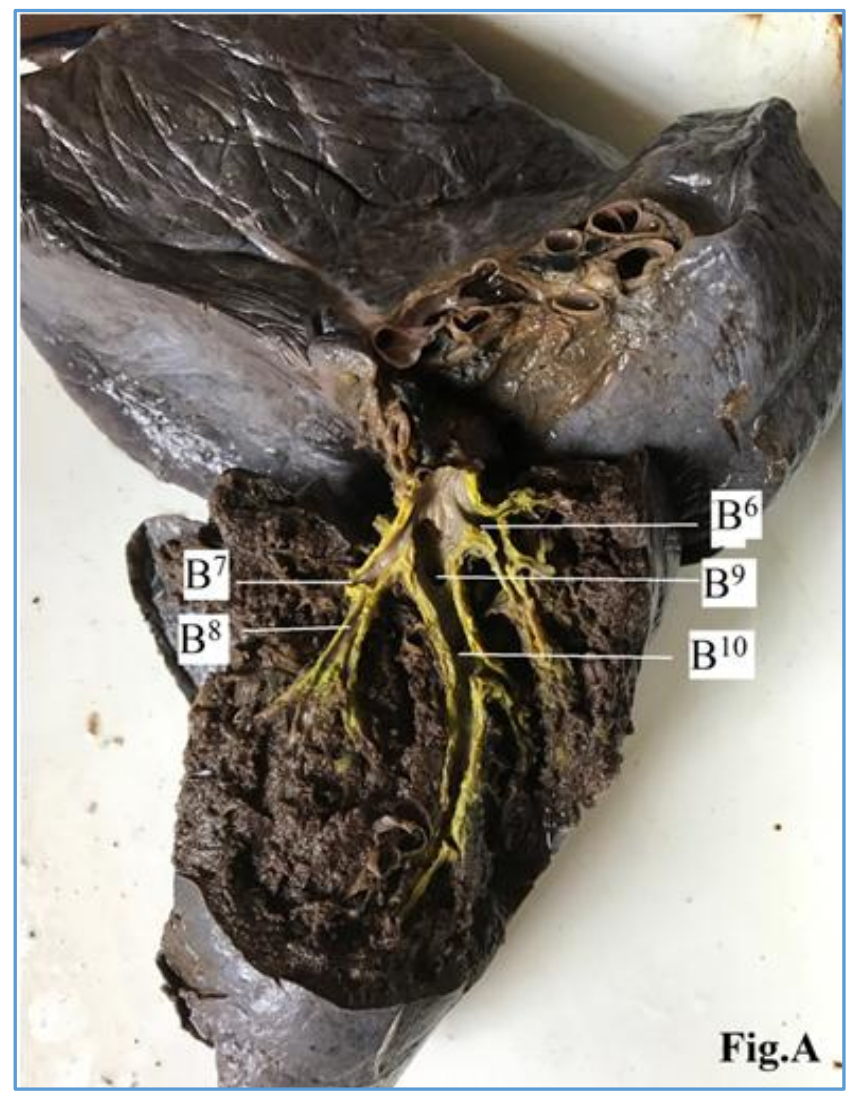

Figure A. Showing the Branching Pattern of Right Lower Lobar Bronchus to Tertiary Bronchi

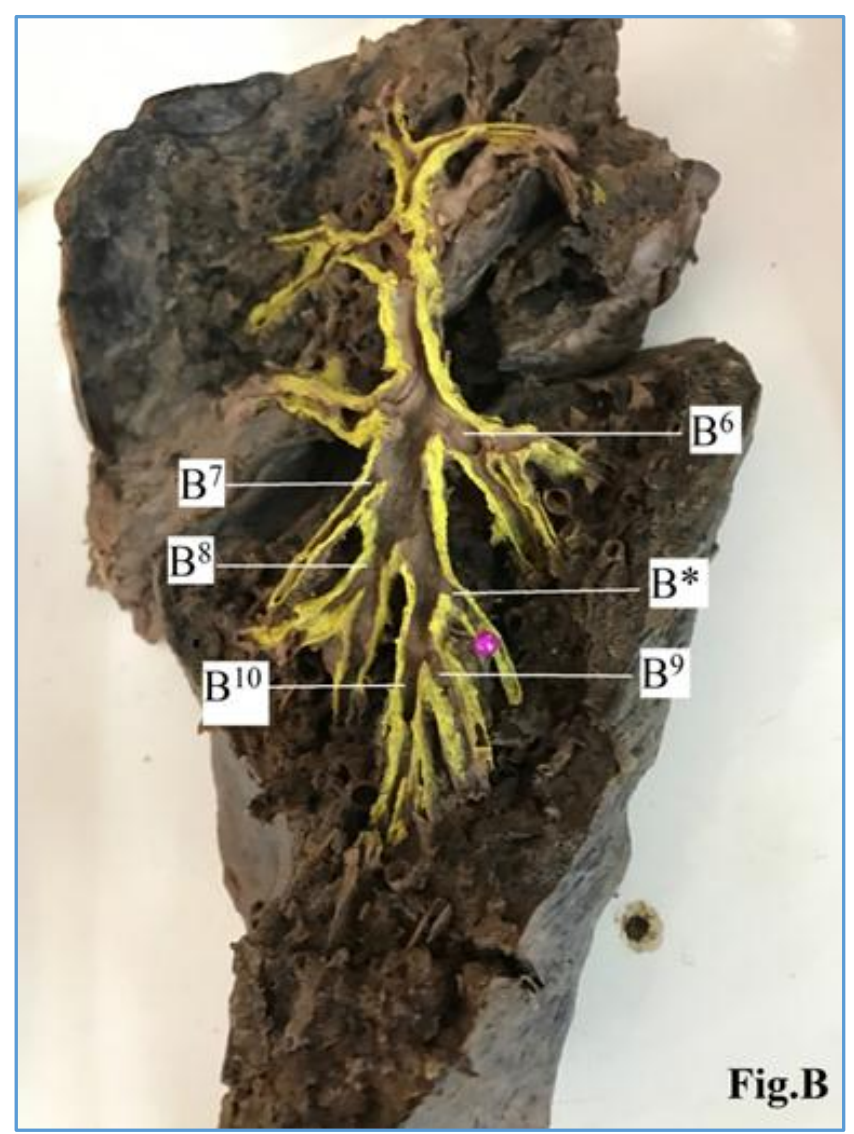

Figure B. Showing the Subapical Bronchus 


\section{DISCUSSION}

Various authors have reported numerous variations of the bronchopulmonary segments. Berg RM, Boyden EA and Smith $\mathrm{FR}^{5}$ reports $\mathrm{B}^{6}$ as a single stem in $96 \%$ with a basal bronchial trunk below this bifurcating in $86 \%$, trifurcating in $6 \%$ and a bizarre pattern in $4 \%$. Ferry and Boyden ${ }^{6}$ describes $\mathrm{B}^{6}$ as a single stem in $92 \%$ and the basal bronchial trunk below this bifurcating in $82 \%$, trifurcating in $14 \%$ and a bizarre pattern in $4 \%$. Kassay ${ }^{7}$ states that lower lobar bronchus divides into 5, 6 and variant segmental bronchi in 57\%, $40.6 \%$ and $2.4 \%$ respectively. In the present study, the branching pattern of lower lobar bronchus into segmental bronchi was seen as follows- Apical $\left(\mathrm{B}^{6}\right)$, Medial basal $\left(\mathrm{B}^{7}\right)$, Anterior basal $\left(\mathrm{B}^{8}\right)$, Lateral basal $\left(\mathrm{B}^{9}\right)$, Posterior basal $\left(\mathrm{B}^{10}\right)$ and Subapical $\left(\mathrm{B}^{*}\right)$ in $100 \%, 89.3 \%, 100 \%, 96.4 \%, 100 \%$ and $17.9 \%$ respectively.

The present study shows the presence of proper subapical bronchus in $17.9 \%$. Most of the earlier studies have observed subapical bronchus as the bronchus of sixth bronchopulmonary segment. Neil $\mathrm{JH}^{8}$ pointed out that the subapical bronchus from medial or lateral or dorsal aspect was seen in $30 \%$. They suggest that the subapical bronchus was homologous to the bronchus constantly seen in lower animals as the posterior branch, the commonest one to persist while others become vestigial and had a tendency to shift towards subapical zone. Boyden ${ }^{9}$ observed that the right lower lobe had a true subapical bronchus and a subapical segment was present in $62 \%$ cases. Maciejewski ${ }^{10}$ confirmed that the subapical segment was present in $40 \%$ cases on the right side. Gray's Anatomy ${ }^{1}$ states that a subsuperior bronchus is present on right side in more than $50 \%$ cases. Patnaik and Saha11 showed the incidence of subsuperior bronchus on the right side as $81 \%$. But this may be due to the fact that they considered those arising from postero-basal aspect of the fraternal basal bronchus as the subsuperior bronchus.

The length and external breadth of the right lower lobe tertiary bronchi were measured (Table No. 2). But we could not find any other report on their dimensions in literature. $\mathrm{B}^{6}$ had the maximum average external breadth $(5.5 \mathrm{~mm})$ and $\mathrm{B}^{9}$ the maximum average length $(1 \mathrm{~mm})$. The subapical bronchus when present had narrow dimensions- an average external breadth of $2.8 \mathrm{~mm}$ and average length of $0.6 \mathrm{~mm}$.

The variation in the patterns of division of tertiary bronchi is due to developmental reasons. The respiratory/lung bud develops at the caudal end of the laryngotracheal diverticulum during the fourth week. Early in the fifth week, the connection of each bronchial bud with the trachea enlarges to form the primordia of main bronchi that branches to form secondary bronchus, which undergoes progressive branching to form the segmental bronchi by the seventh week. As this occurs, the surrounding mesenchyme also divides and forms the primordium of a bronchopulmonary segment. ${ }^{12}$ Occasionally, the patterns may vary during development.

\section{CONCLUSION}

The present study was conducted on 56 human right lungs to analyse the branching pattern of the tertiary bronchi of its lower lobe. Apical $\left(\mathrm{B}^{6}\right)$, Lateral basal $\left(\mathrm{B}^{9}\right)$ and Posterior basal $\left(\mathrm{B}^{10}\right)$ segments were constantly present, whereas Medial basal $\left(\mathrm{B}^{7}\right)$ and Anterior basal $\left(\mathrm{B}^{8}\right)$ were seen in $89.3 \%$ and $96.4 \%$ respectively. A Subapical segment $\left(\mathrm{B}^{*}\right)$ which is an occasional segment that arises as a separate bronchus from the right inferior lobar bronchus was seen in $17.9 \%$. The length and external breadth of the right lower lobe tertiary bronchi were also measured and $\mathrm{B}^{6}$ had the maximum average external breadth $(5.5 \mathrm{~mm})$ and $\mathrm{B}^{9}$ the maximum average length $(1 \mathrm{~mm})$. The knowledge of bronchopulmonary segments is very helpful in diagnostic, surgical and clinical procedures like postural drainage..$^{13}$

\section{REFERENCES}

[1] Standring S. Gray's anatomy: the anatomical basis of clinical practice. $40^{\text {th }}$ edn. Churchill Livingston, Elsevier 2008:992-1000.

[2] Snell RS. Clinical anatomy by regions. Lippincott Williams and Wilkins 2000;6:127.

[3] Chassagnon G, Morel B, Carpentier E, et al. Tracheobronchial branching abnormalities: lobebased classification scheme. Radio Graphics 2016;36(2):358-73.

[4] Boyden EA. Segmental anatomy of the lungs. New York, NY: McGraw-Hill 1955.

[5] Berg RM, Boyden EA, Smith FR. An analysis of variations of the segmental bronchi of the left lower lobe of fifty dissected and ten injected lungs. J thoracic surgery 1949;18(2):216-37.

[6] Ferry RM, Boyden EA. Variations in the bronchovascular patterns of the right lower lobe of fifty lungs. J Thorac Surg 1951;22(2):188-201.

[7] Kassay D. Observations on one hundred cases of bronchial foreign body. Archives of Otolaryngology 1960;71:42-58.

[8] Neil JH. Azygos lobes of the lung, and terminology of the bronchopulmonary segments of the bronchial tree. Ann Otol Rhinol Laryngol 1950;59(2):409-13.

[9] Boyden EA. A critique of the international nomenclature on bronchopulmonary segments. Dis Chest 1953;23(3):266-9.

[10] Maciejewski R. The venous drainage of the apical segment of the right lower pulmonary lobe. Acta Anatomica 1994;150:217-21.

[11] Patnaik VVG, Saha JC. Incidence of subsuperior bronchus - morphological and bronchographic study. J Anat Soc India 1999;48(2):99-104.

[12] Moore KL, Persaud TVN, Torchia MG. Before we are born. $8^{\text {th }}$ edn. Essentials of embryology and birth defects. Elsevier 2016;9:132.

[13] Bhaudas KJ. A study of common patterns of the subsuperior bronchi in right and left human lungs. International Journal of Contemporary Surgery 2015;3(2):13-7. 